\title{
Mitigation of Platinum Depletion in Platinum Diffused Single Phase Bond Coat on CMSX-4 Superalloy
}

\author{
Mingwen Bai ${ }^{1,2, * \mathbb{C}}$, Ying Chen ${ }^{1}$, Yongle Sun ${ }^{3} \mathbb{D}$ and Ping Xiao ${ }^{1}$ \\ 1 Department of Materials, University of Manchester, Manchester M13 9PL, UK; \\ ying.chen-2@manchester.ac.uk (Y.C.); Ping.Xiao@manchester.ac.uk (P.X.) \\ 2 Institute for Future Transport \& Cities, Coventry University, Coventry CV1 5FB, UK \\ 3 Welding Engineering and Laser Processing Centre, School of Aerospace, Transport and Manufacturing, \\ Cranfield University, Cranfield MK43 0AL, UK; yongle.sun@cranfield.ac.uk \\ * Correspondence: mingwen.bai@coventry.ac.uk
}

check for updates

Citation: Bai, M.; Chen, Y.; Sun, Y.; Xiao, P. Mitigation of Platinum Depletion in Platinum Diffused Single Phase Bond Coat on CMSX-4 Superalloy. Coatings 2021, 11, 669. https://doi.org/10.3390/ coatings11060669

\section{Academic Editor: Philipp}

Vladimirovich Kiryukhantsev-

Korneev

Received: 11 May 2021

Accepted: 28 May 2021

Published: 31 May 2021

Publisher's Note: MDPI stays neutral with regard to jurisdictional claims in published maps and institutional affiliations.

Copyright: (C) 2021 by the authors. Licensee MDPI, Basel, Switzerland. This article is an open access article distributed under the terms and conditions of the Creative Commons Attribution (CC BY) license (https:/ / creativecommons.org/licenses/by/ $4.0 /)$.

\begin{abstract}
Pt-diffused bond coat with a mixture of $\gamma / \gamma^{\prime}$ phase has just been developed in the recent decades as a cheaper alternative to the Pt-enriched $\beta$-phase Aluminide bond coat that contains a higher content of $\mathrm{Al}$. However, concerns are raised on the inevitable depletion of $\mathrm{Pt}$ near the coating interface that may endanger the component after long-term service. In this study, modified Pt-diffused bond coats with a single phase $\left(\gamma\right.$ or $\left.\gamma^{\prime}\right)$ were made by applying selective etching on CMSX-4 single crystal superalloys prior to the electroplating of Pt. The single-phase bond coats show distinctive diffusion behaviour in comparison with the conventional $\gamma / \gamma^{\prime}$ bond coat. Surprisingly, Pt remains more stable in the $\gamma^{\prime}$-phase bond coat with significantly less depletion after diffusion, which implies a potential in saving a considerable amount of Pt. On the other hand, however, the depletion of $\mathrm{Pt}$ is more severe in the $\gamma$-phase bond coat. The mechanism that governs the diffusion behavior of Pt in the $\gamma$ and $\gamma^{\prime}$-phase was also discussed that mainly concerns with thermodynamic and kinetic factors.
\end{abstract}

Keywords: bond coat; platinum; diffusion; thermodynamic; thermal barrier coatings

\section{Introduction}

Thermal-barrier coatings (TBCs) are widely applied in the hot section of aero-engines to protect the turbine blade and improve energy efficiency [1-3]. In general, a TBCs system consists of an oxidation-resistant bond coat on a Ni-based superalloy, and an yttriastabilized zirconia (YSZ) topcoat deposited by electron beam-physical vapour deposition (EBPVD) or air-plasma spray (APS). When exposed to high temperatures, a thermally grown oxide (TGO) layer forms between the topcoat and the bond coat as a protection from further oxidation attack. Nevertheless, it is essential to maintain a strong bonding at the TGO/bond coat interface where most TBCs' failures occur [4,5]. An adequate selection of the bond coat therefore becomes the most critical factor to ensure the durability of TBCs on the turbine blades. So far, there are three major classes of bond coat in the aero-plane industry [6,7]: (1) Overlay MCrAlY (M = Ni, Co), which is composed of $\beta-\mathrm{NiAl}$ and $\gamma-\mathrm{Ni}$ (or $\gamma^{\prime}$-Ni $\mathrm{Ni}_{3} \mathrm{Al}$ ) phase; (2) Pt-aluminide $\beta$-phase bond coat; and (3) Pt-diffused $\gamma / \gamma^{\prime}$ phase bond coat, which is the patented platinum diffusion treatment to the surface of a superalloy, resulting in a $\gamma+\gamma^{\prime}$ two-phased coating [6,7]. Compared with the former two classes, the Pt-diffused $\gamma / \gamma^{\prime}$ bond coat has certain advantages because of a simplified fabrication procedure with no aluminizing process [8,9] and negligible rumpling after thermal cycling due to higher creep resistance and better compatibility with Ni-based superalloys [9,10].

However, concerns are always raised on a Pt-diffused $\gamma / \gamma^{\prime}$ bond coat due to the significant inwards diffusion of Pt towards the substrate during long-term heat treatment [11]. A depletion of $\mathrm{Pt}$ near the TGO/bond coat interface fails to maintain strong adhesion of TGO to bond coat, and it results in a compromised oxidation resistance and ultimate TBCs 
failures [12-15]. In addition, the high material cost of Pt is another big concern. In general, the cost of YSZ ceramic powder is GBP 20 to GBP 50 per kg, and the cost of MCrAlY powder is GBP 30 to GBP 70 per kg. However, the cost of Pt is above GBP 27,000 per $\mathrm{kg}$, and the cost of $\mathrm{Pt}$ salt ( $\mathrm{Q}$ salt, $\left[\mathrm{Pt}\left(\mathrm{NH}_{3}\right)_{4}\right] \mathrm{HPO}_{4}, 0.5 \%$ w/w) containing the equivalent amount of $\mathrm{Pt}$ is even 2-3 times higher, which is above GBP 90,000. The weight usage of $\mathrm{Pt}$ on each turbine blade is $1 / 6$ to $1 / 3$ of the YSZ powder (if we assume the Pt layer is $10 \mu \mathrm{m}$ thick while the YSZ layer is 100-200 $\mu \mathrm{m}$ thick. The density of Pt and YSZ is $21.4 \mathrm{~g} / \mathrm{cm}^{3}$ and $6.10 \mathrm{~g} / \mathrm{cm}^{3}$, respectively). It clearly indicates that $\mathrm{Pt}$ takes a considerable proportion in the overall cost of each TBCs coated turbine blade. Unfortunately, the current technique is unable to reduce the usage of $\mathrm{Pt}$ in TBCs as it would put the turbine engines at risks. In this study, the fabrication process of the Pt-diffused bond coat will be re-designed by applying selective etching methods on the Ni-based single crystal superalloys prior to the electroplating of Pt. This method could selectively remove one certain phase while the other phase remains on the substrate surface. Using this method, a single phase $\left(\gamma^{\prime}\right.$ or $\left.\gamma\right)$ bond coat with an enrichment of Pt could be in situ prepared on the superalloy substrate. This design is aiming to develop a new bond coat with less Pt but required performance. The possible thermodynamic and kinetic mechanism controlling the diffusion of $\mathrm{Pt}$ in the $\gamma^{\prime}$ and $\gamma$ phase will also be discussed.

\section{Materials and Methods}

\subsection{Sample Preparation}

Single phase Pt-diffused bond coats were fabricated on industrial standard CMSX-4 single crystal superalloys with a size of $20 \mathrm{~mm} \times 10 \mathrm{~mm} \times 2 \mathrm{~mm}$. The substrates had been well treated after standard heat treatment and examined to have perfect cuboidal microstructure with substrate surface normal aligned to the [200] axis. The substrate surface was grinded by 320-grit $\mathrm{SiC}$ paper, degreased by ethanol, and then cleaned by deionized water in an ultrasonic bath. Single phase Pt-diffused bond coats are fabricated according to the new procedures as shown in Figure 1. In the standard fabrication procedure of Pt-diffused $\gamma / \gamma^{\prime}$ bond coats, the pre-treatment of the CMSX-4 substrate is normally done by grit blasting to increase the surface roughness for a better adhesion. This is followed by electroplating of a Pt thin layer with a thickness of 10-12 $\mu \mathrm{m}$ on the CMSX-4 surface and then vacuum heat treatment is applied during which Pt will diffuse into the CMSX-4 substrate and form a Pt-diffused layer with a mixed $\gamma / \gamma^{\prime}$ phase. On the other hand, when selective etching is applied on the unique microstructure of the CMSX-4 single crystal superalloy, it could selectively remove either $\gamma^{\prime}$-cubes or $\gamma$-matrix while the other phase remains attached on the surface as a coating with a certain thickness. The use of $\gamma^{\prime}$-etching is a traditional pre-treatment method for electroplating, which could effectively remove the oxide layer on the alloy surface and chemically activate the alloy surface to ensure a strong adhesion. Meanwhile, $\gamma$-etching can be done by using electrolyte etching, which is always used as an effective method to extract $\gamma^{\prime}$-precipitates from the $\gamma$-matrix for the observation of morphology of superalloys after certain heat treatments. After selective etching, $\mathrm{Pt}$ is then electroplated on the etched substrate filling the voids (or matrix) and forms a composite layer of $\mathrm{Pt}$ and $\gamma^{\prime}$-cubes (or $\gamma$-matrix). Finally, after vacuum heat treatment, $\mathrm{Pt}$ diffuses into the $\gamma^{\prime}$-cubes or $\gamma$-matrix and forms a single-phase Pt-enriched layer.

For $\gamma^{\prime}$-etching, a solution which contains $150 \sim 170 \mathrm{~mL} / \mathrm{L} \mathrm{HCl}(37 \%)$ and $250 \sim 330 \mathrm{~g} / \mathrm{L}$ $\mathrm{FeCl}_{3} \cdot 6 \mathrm{H}_{2} \mathrm{O}$ was used as $\gamma^{\prime}$-etchant. Substrates were immersed in the solution for 1-10 min. For $\gamma$-etching, electrolyte etching, which is an anodic dissolution process that uses electrical and chemical reactions, was applied with $10 \% \mathrm{H}_{3} \mathrm{PO}_{4}-90 \% \mathrm{H}_{2} \mathrm{O}$ solution under an electric field of 3-4 V and $120 \mathrm{~mA} / \mathrm{cm}^{2}$ [16]. Platinum foil was used as cathode, and substrates were etched for 1-10 min under a constant current density of $100 \sim 200 \mathrm{~mA} / \mathrm{cm}^{2}$ with a slow magnetic stirring. After etching, all substrates were rinsed in boiling sodium hydroxide solution $(\mathrm{NaOH}, 5 \%)$ for $10 \mathrm{~min}$ to remove the residual acid and then washed by deionized water. After selective etching, platinum was electroplated on the substrate surface by using Q salt (Tetraammineplatinum (II) hydrogen phosphate, Johnson Matthey, London, UK). 
After electroplating, all substrates were carefully washed by deionized water and dried at ambient temperatures for overnight.

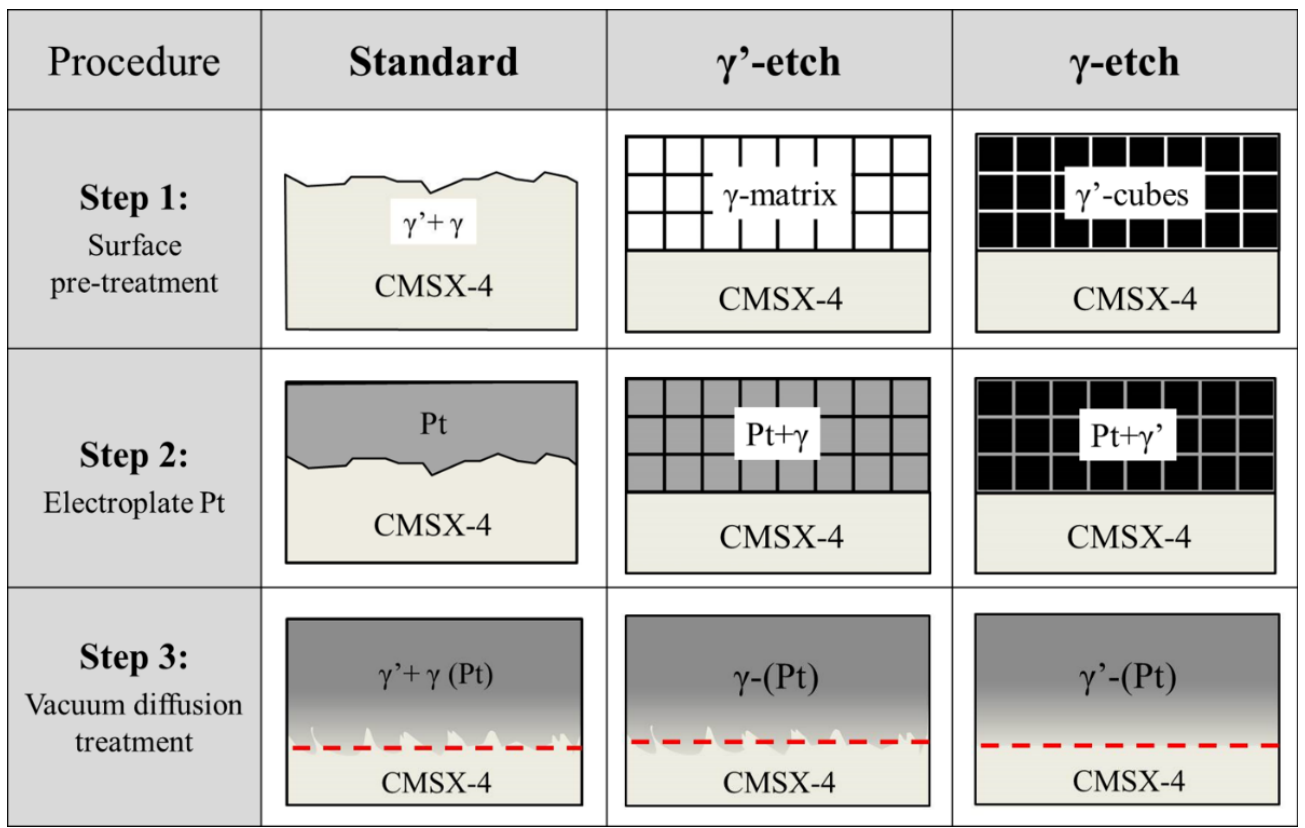

Figure 1. Schematic illustrations show the microstructural evolution on the cross-sections of singlephase Pt-diffused bond coat fabricated by selective etching.

\subsection{Thermal Treatment}

Diffusion treatment was performed at $1150{ }^{\circ} \mathrm{C}$ for $2 \mathrm{~h}$ in a vacuum tube furnace (Carbolite, Sheffield, UK) with a turbo vacuum pump (Turbocarts, Edwards, West Sussex, UK) at a pressure of $\sim 10^{-5}$ mbar. The samples were then defined as the as-received bond coats. Detailed information on the fabrication process can also be found in reference [17]. Isothermal oxidation was performed at $1150{ }^{\circ} \mathrm{C}$ in a thermal cycling furnace $\left(\mathrm{CM}^{\mathrm{TM}}\right.$, Bloomfield, NJ, USA) with an automatic lifting platform and a powerful cooling fan. The heating/cooling was controlled at a rate of $100{ }^{\circ} \mathrm{C} / \mathrm{min}$.

\subsection{Characterization Methods}

Scanning electron microscope (SEM, Philips XL30, Eindhoven, The Netherlands and FEI Quanta 650, Lausanne, Switzerland), accompanied with energy-dispersive X-ray spectroscopy (EDX), was used to examine the microstructure and element mappings on the cross-section and surface. Electron probe micro-analyzer (EPMA, Cameca SX 100, Gennevilliers, France) was used for alloying element mapping (e.g., $\mathrm{Pt}, \mathrm{Al}, \mathrm{Ta}$, etc.). Electron beam was accelerated at $20 \mathrm{kV}$, with a beam size of $1 \mu \mathrm{m}$, a beam current of $100 \mathrm{nA}$, and a dwell time per pixel of $20 \mathrm{mS}$.

To observe the inwards diffusion of $\mathrm{Pt}$, the average concentration profiles of $\mathrm{Pt}$ were obtained via the Image Processing Toolbox using MATLAB ${ }^{\circledR}$ (MathWorks, R2020b, Natick, MA, USA) by accumulating and normalizing the line profiles on the cross-sections normal to the TGO/bond coat interface from the EPMA mappings at an area of $250 \mu \mathrm{m} \times 150 \mu \mathrm{m}$. The average compositions of $\gamma^{\prime}$-phase coatings were measured by using energy dispersive X-ray fluorescence analysis (EDXRF, MiniPal 4 PANalytical, Malvern Panalytical Ltd., Malvern, UK).

\subsection{Thermodynamic Calculations}

The chemical activity of $\mathrm{Pt}$ in the binary phase system of $\mathrm{PtX}$ and $\mathrm{Pt}_{3} \mathrm{X}$ at $1150{ }^{\circ} \mathrm{C}$ was calculated by Thermo-Calc with $\mathrm{TCNi}_{6}$ database. The TCS Ni-based superalloy database $\left(\mathrm{TCNi}_{6}\right)$ [18] was employed following the well-established CALPHAD technique [19]. The 
use of the Thermo-Calc software on Nickel superalloys and bond coat systems for high temperature applications has been validated by our previous works [20-23].

\section{Results}

\subsection{Standard Pt-Diffused $\gamma / \gamma^{\prime}$-Phase Bond Coat}

Figure 2 shows the cross-sectional backscattered electron (BSE) images of the conventional Pt-diffused $\gamma / \gamma^{\prime}$ bond coat: Figure 2A, as-received; Figure 2B, after $50 \mathrm{~h}$ diffusion at $1150{ }^{\circ} \mathrm{C}$ in vacuum; and Figure $2 \mathrm{C}$, after $50 \mathrm{~h}$ oxidation at $1150{ }^{\circ} \mathrm{C}$ in air. Figure 3 shows the EPMA mappings and concentration profiles of Pt on the cross-sections of the standard Pt-diffused $\gamma / \gamma^{\prime}$ bond coat normal to the TGO/bond coat interface. It is worth noting that under the BSE mode, heavy elements (especially $\mathrm{Pt}$ ) can strongly backscatter electrons, thus appears brighter. After heat treatment, significant inwards diffusion of $\mathrm{Pt}$ towards the substrate is observed. The average thickness of the Pt-diffused $\gamma / \gamma^{\prime}$ layer (in bright colour) nearly doubled from $30 \mu \mathrm{m}$ to $59 \mu \mathrm{m}$ after oxidation. The formation of a thin $\gamma$-phase layer with less Pt enriched (in dark colour) is also observed underneath the TGO layer after oxidation. In addition, the depletion of $\mathrm{Pt}$ is worse after oxidation than that after diffusion in vacuum. It indicates that the oxidation process accelerates the depletion of $\mathrm{Pt}$, results in a much lower content of Pt near the TGO and compromises the oxidation resistance. For this reason, what manufactures would normally do is electroplating excessive $\mathrm{Pt}(>10 \mu \mathrm{m})$ on superalloys in order to compensate for the loss of Pt that will deplete during oxidation. This, however, implies that less $\mathrm{Pt}$ would be needed if the issue in the depletion of $\mathrm{Pt}$ is solved or, in other words, if $\mathrm{Pt}$ remains stable near the surface during heat treatment.
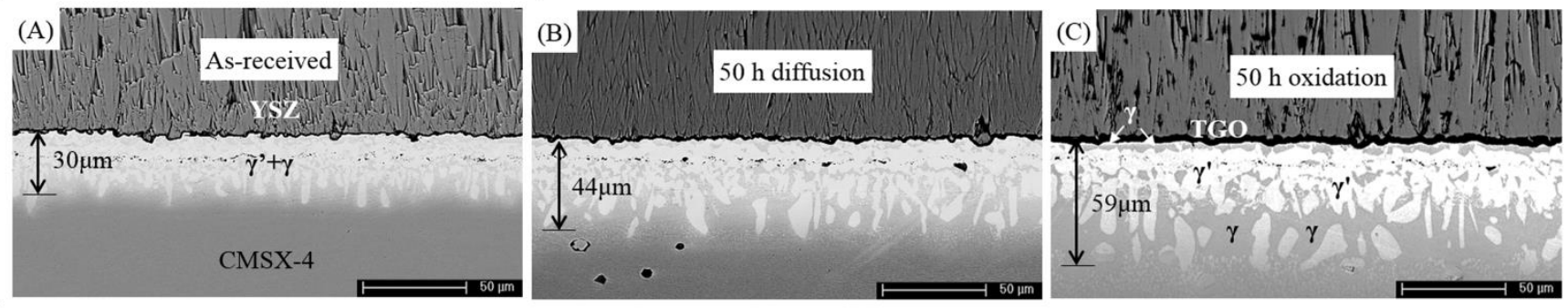

Figure 2. Cross-sectional BSE images of standard Pt-diffused $\gamma^{\prime}+\gamma$ bond coat: (A) as-received; (B) $50 \mathrm{~h}$ diffusion in vacuum at $1150{ }^{\circ} \mathrm{C}$; (C) $50 \mathrm{~h}$ oxidation in air at $1150{ }^{\circ} \mathrm{C}$.

\subsection{Selective Etching Process}

Figure 4A,B shows the surface and cross-sectional SEM images of a $\gamma^{\prime}$-etched CMSX-4 substrate. For $\gamma^{\prime}$-etching, $\gamma^{\prime}$-cubes were etched away with the formation of $\gamma$-matrix and square holes. A $\gamma$-matrix layer with a uniform thickness of 5-10 $\mu \mathrm{m}$ can be obtained by $\gamma^{\prime}$-etching for 1-3 min (Figure 4B). Similarly, in Figure 4C-E, the use of $\gamma$-etching completely etched away $\gamma$-matrix and retained the $\gamma^{\prime}$-cubes with an even size of less than $1 \mu \mathrm{m}$ on the CMSX-4 substrate. In Figure 4C, internal $\gamma^{\prime}$-cubes were exposed by manually scratching off part of the $\gamma$-etched substrate surface and it shows an orderly stacking structure and arrangement with no disruptions. Even though $\gamma^{\prime}$-cubes were isolated with no supporting matrix, these cubes still stayed intact within the original microstructure on the substrate surface mainly by the electrostatic attraction force. In this way, a uniform and dense $\gamma^{\prime}$-cubes layer is therefore obtained on the CMSX-4 substrate with a smooth and straight interface between the etched and non-etched area. In addition, the etched thickness increases linearly with etching time, and a $\gamma^{\prime}$-phase layer $(80-100 \mu \mathrm{m})$ can be obtained by $\gamma$-etching for $10 \mathrm{~min}$. Accordingly, by using selective etching methods, single phase $\left(\gamma\right.$ or $\left.\gamma^{\prime}\right)$ layers were well prepared on the CMSX-4 substrate. 

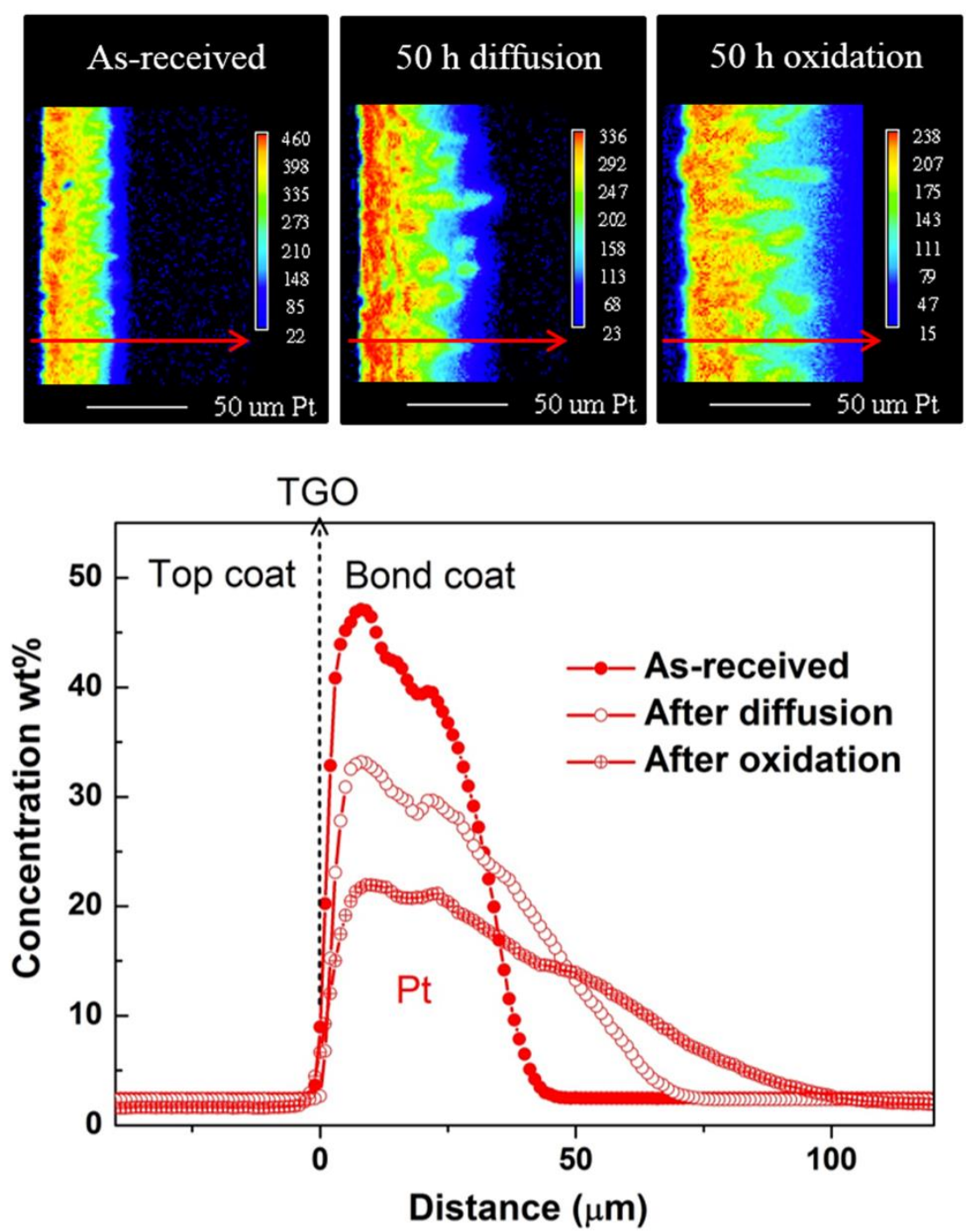

Figure 3. EPMA mappings and concentration profiles of Pt on the cross-sections of the standard Pt-diffused $\gamma / \gamma^{\prime}$ bond coat normal to the TGO/bond coat interface.

Figure 5 shows the EPMA maps of the main alloying elements on the cross-section of the $\gamma^{\prime}$-phase layer after $\gamma$-etching. The accurate compositions of the $\gamma^{\prime}$-phase layer and the CMSX-4 substrate were measured by using XRF and are listed in Table 1. It is observed that the removal of the $\gamma$-matrix has caused an increase in the concentration of $\mathrm{Al}(5.6 \mathrm{wt} \%$ to $9.0 \mathrm{wt} \%$ ), Ti and Ta, as well as a decrease in the concentration of $\mathrm{Cr}, \mathrm{Co}, \mathrm{W}$, and Re. Further discussion will be made on the compositional factors affecting the diffusion of Pt.

Table 1. Chemical compositions of CMSX-4 substrate and $\gamma^{\prime}$-phase layer (wt \%).

\begin{tabular}{cccccccccc}
\hline & Ni & Cr & Co & Al & Mo & W & Ti & Re & Ta \\
\hline CMSX-4 substrate & 63.4 & 5.8 & 9.3 & 5.6 & 0.5 & 5.5 & 0.9 & 1.3 & 7.4 \\
$\gamma^{\prime}$-phase layer & 66.3 & 2.2 & 6.3 & 9.0 & 0.4 & 4.3 & 1.1 & 0.2 & 10.1 \\
\hline
\end{tabular}



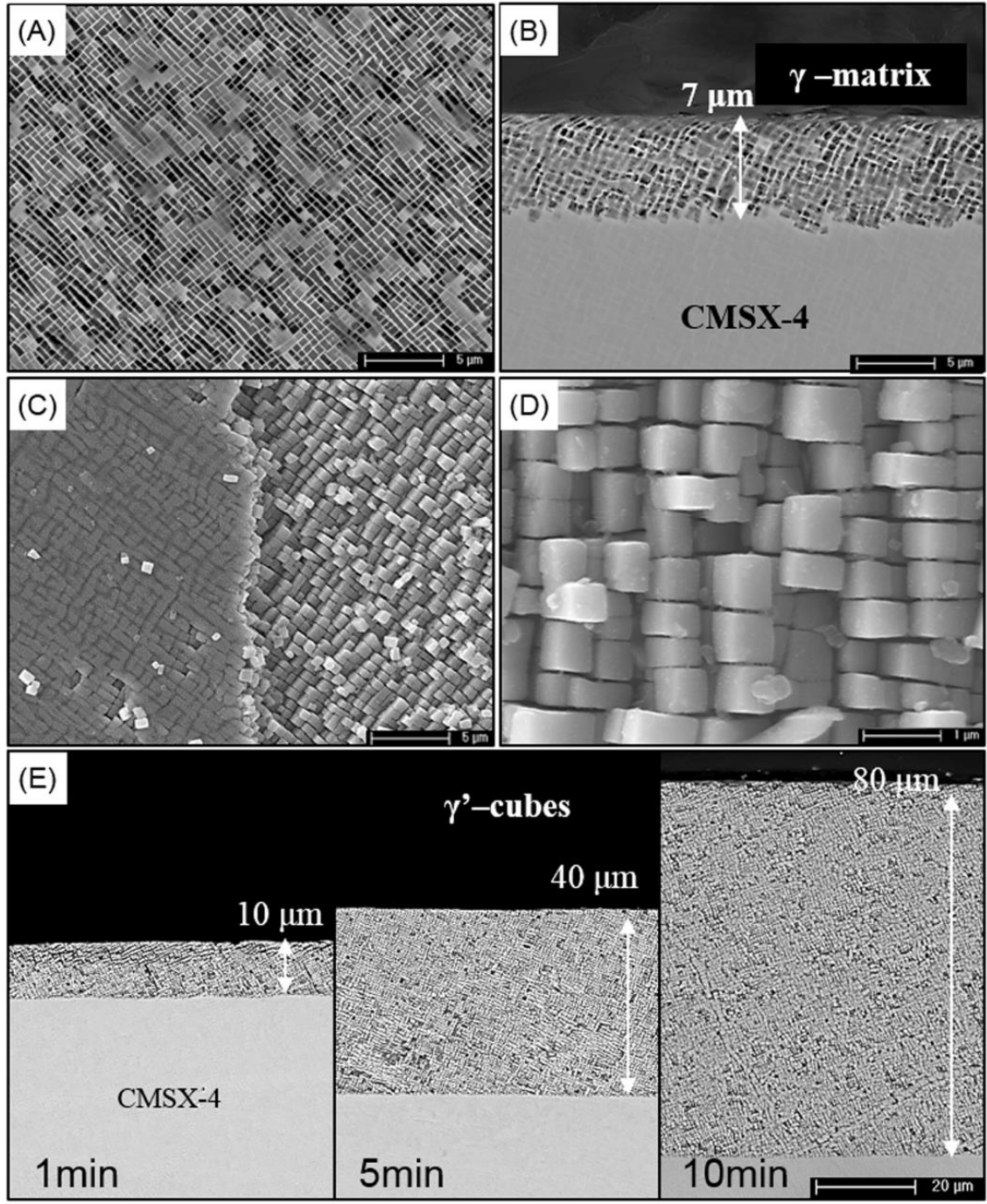

Figure 4. (A) Surface and (B) cross-sectional SEM images of $\gamma^{\prime}$-etched substrate; (C) + (D) surface and (E) cross-sectional SEM images of $\gamma$-etched substrate with different etching times. The inner $\gamma^{\prime}$-cubes were exposed by scratching the surface off.
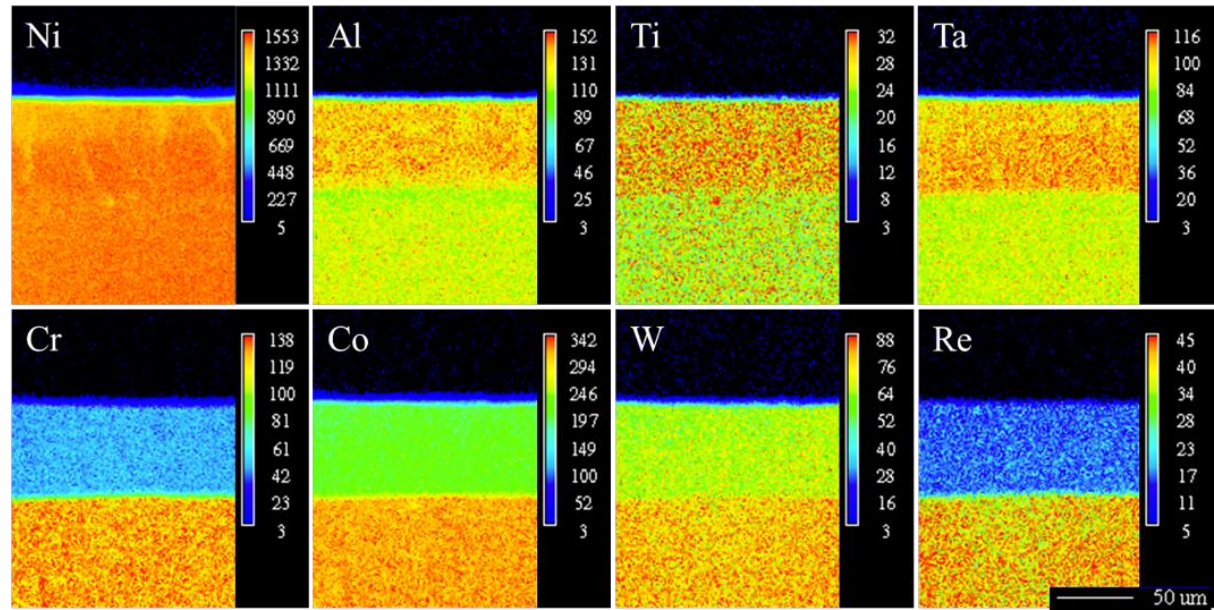

Figure 5. EPMA mappings on the cross-section of the $\gamma^{\prime}$-phase layer. (The colour scale on the right side indicates the elemental concentrations.) 


\subsection{Pt-Diffused Single Phase Bond Coat}

Figure 6 shows the cross-sectional BSE images of the 6A as-electroplated $\gamma^{\prime}$-etched substrate and $6 \mathrm{~B}$ after vacuum heat treatment at $1150{ }^{\circ} \mathrm{C}$ for $2 \mathrm{~h}$. During electroplating, after the $\gamma$-Ni matrix was filled with Pt, an additional Pt layer with a thickness of $7 \mu \mathrm{m}$ was electroplated on the surface to provide enough Pt for the oxidation test as $\gamma^{\prime}$-etching can only remove a limited amount of the $\gamma^{\prime}$-phase. After vacuum heat treatment, a $\gamma$-phase layer $(\sim 7 \mu \mathrm{m})$ with less Pt-diffused is observed near the surface, and a larger proportion of $\mathrm{Pt}$ is in the inner substrate with the formation of a mixed layer of a $\gamma / \gamma^{\prime}$-phase and a similar microstructure with that of the standard $\gamma / \gamma^{\prime}$ bond coat. It indicates that during vacuum heat treatment, Pt passed though the $\gamma$-phase layer and diffused further into the substrate. Accordingly, the formation of the $\gamma$-phase layer has a negative effect in stabilizing $\mathrm{Pt}$ as it accelerated the depletion of $\mathrm{Pt}$ during heat treatment.
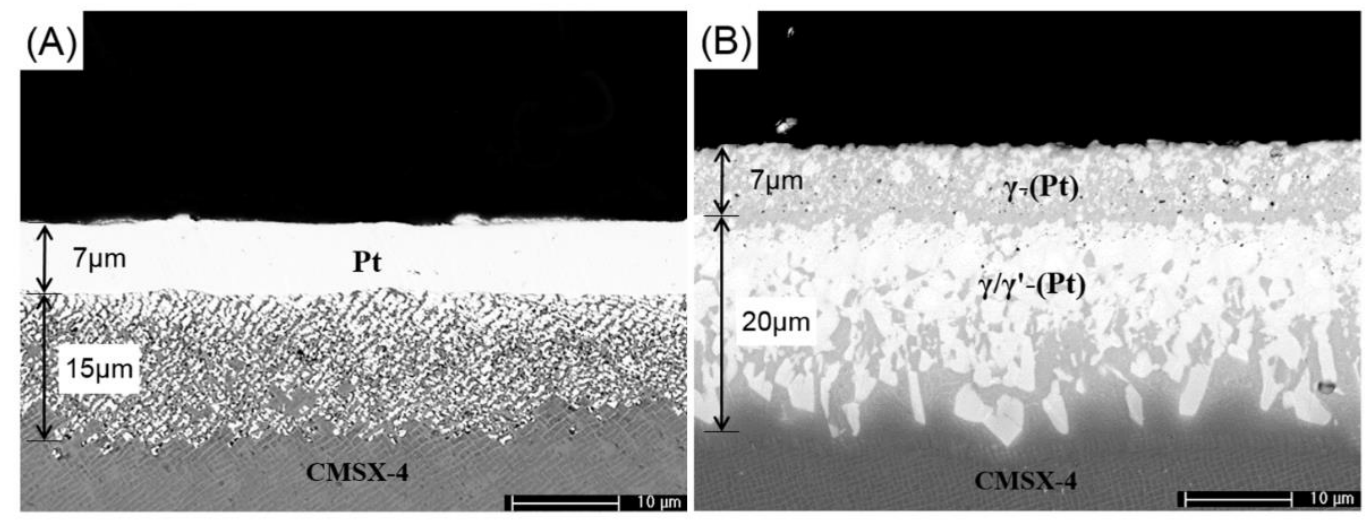

Figure 6. Cross-sectional BSE images of the (A) as-electroplated $\gamma^{\prime}$-etched substrate and (B) after heat treatment at $1150{ }^{\circ} \mathrm{C}$ for $2 \mathrm{~h}$ in vacuum.

Figure 7 shows the cross-sectional BSE images of the Pt-diffused $\gamma^{\prime}$-phase bond coat $7 \mathrm{~A}, \mathrm{~B}$ as-electroplated; $7 \mathrm{C}$, as-received bond coat after vacuum heat treatment at $1150{ }^{\circ} \mathrm{C}$ for $2 \mathrm{~h}$; 7D, after diffusion treatment in vacuum at $1150{ }^{\circ} \mathrm{C}$ for additional $50 \mathrm{~h}$. After electroplating, a coherent composite layer comprising the Pt-matrix and $\gamma^{\prime}$-cubes with a uniform thickness of $14 \mu \mathrm{m}$ is obtained on the CMSX-4 substrate. In this composite layer, $\gamma^{\prime}$-cubes are periodically embedded in the Pt-matrix, and remain the same microstructure, arrangement and orientation as in the CMSX-4 substrate. In other words, Pt has completely replaced the $\gamma$-phase matrix in CMSX-4 with no disruption of its original periodic microstructure. If so, the volume fraction of $\mathrm{Pt}$ in the composite layer of Pt-matrix $/ \gamma^{\prime}$-cubes is then around $23 \%$ while the $\gamma^{\prime}$-cubes take the other $77 \%$, which is an estimation according to the measured volume fraction of the $\gamma$-matrix in a CMSX-4 single crystal superalloy [24]. After vacuum heat treatment, it is observed that $\mathrm{Pt}$ is uniformly dissolved in the $\gamma^{\prime}$-phase, and a coherent layer of the Pt-diffused $\gamma^{\prime}$-phase with a thickness of $14 \mu \mathrm{m}$ forms on the CMSX-4 substrate with a clear and smooth coating/substrate interface. Surprisingly, the diffusion of Pt only occurred in the surface plane but not in the surface normal. Furthermore, $\mathrm{Pt}$ remained stable in the $\gamma^{\prime}$-phase layer with no depletion even after an additional diffusion treatment at $1150^{\circ} \mathrm{C}$ for $50 \mathrm{~h}$ in vacuum. All of these results indicate that the $\gamma^{\prime}$-phase layer effectively inhibits the inwards diffusion of Pt towards the CMSX-4 substrate and results in a more stable Pt-diffused layer with no depletion during heat treatment.

Figure 8 shows the cross-sectional BSE images and EPMA mappings of $8 \mathrm{~A}$ the standard Pt-diffused $\gamma / \gamma^{\prime}$ bond coat and 8B the Pt-diffused $\gamma^{\prime}$-phase bond coat after oxidation at $1150{ }^{\circ} \mathrm{C}$ for $50 \mathrm{~h}$. After oxidation, the Pt-diffused $\gamma^{\prime}$-phase bond coat remains uniform as a coherent $\gamma^{\prime}$-phase layer on the substrate. The concentration of $\mathrm{Pt}$ and $\mathrm{Al}$ in the Pt-diffused $\gamma^{\prime}$-phase bond coat beneath the TGO layer remains high with less depletion. 


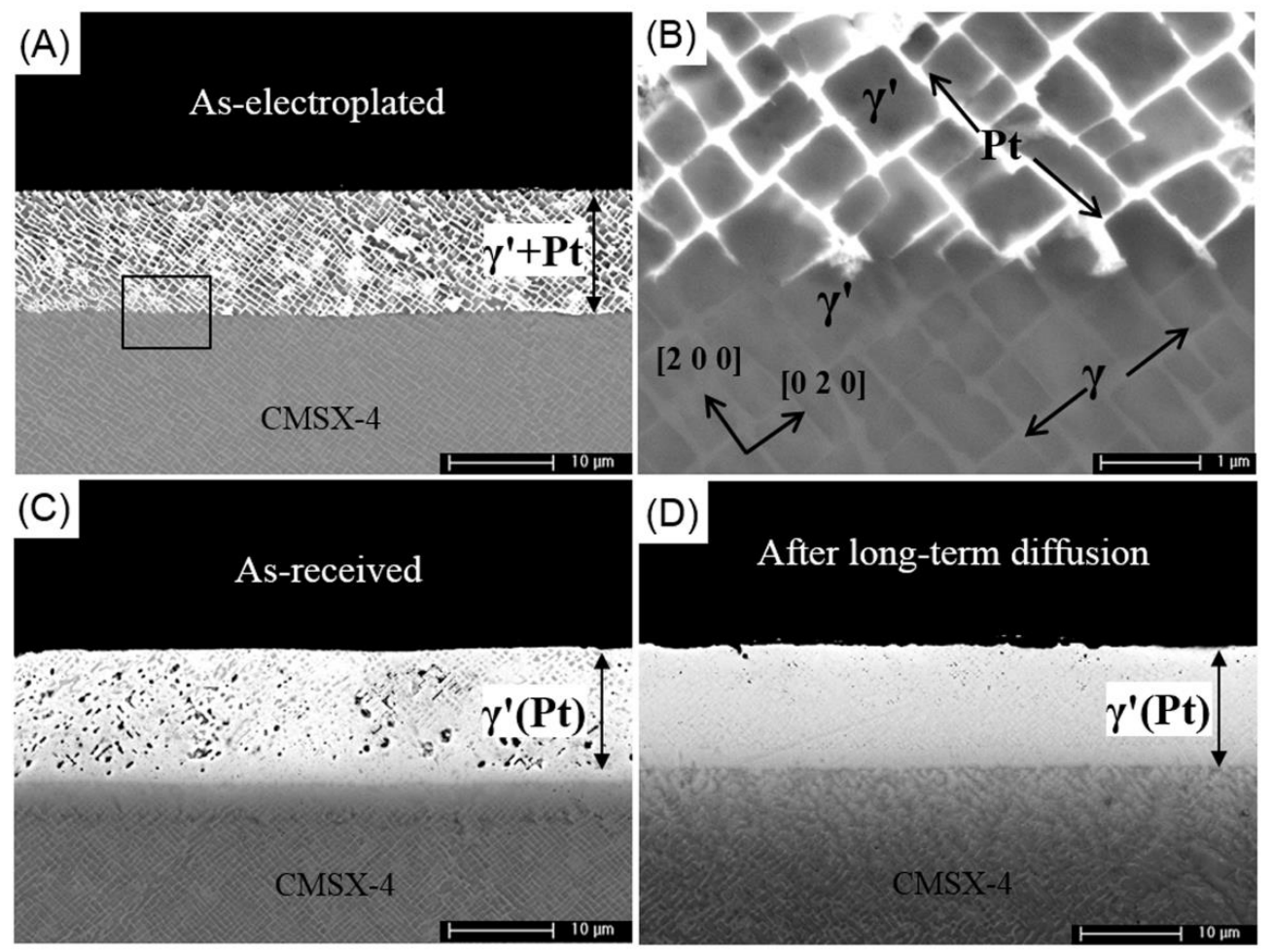

Figure 7. Cross-sectional BSE images of the Pt-diffused $\gamma^{\prime}$-phase bond coat; (A) the as-electroplated $\gamma$ etched substrate; (B) enlarged image at the substrate/coating interface; (C) as-received after vacuum heat treatment at $1150{ }^{\circ} \mathrm{C}$ for $2 \mathrm{~h}$; and (D) after additional $50 \mathrm{~h}$ in vacuum at $1150{ }^{\circ} \mathrm{C}$.

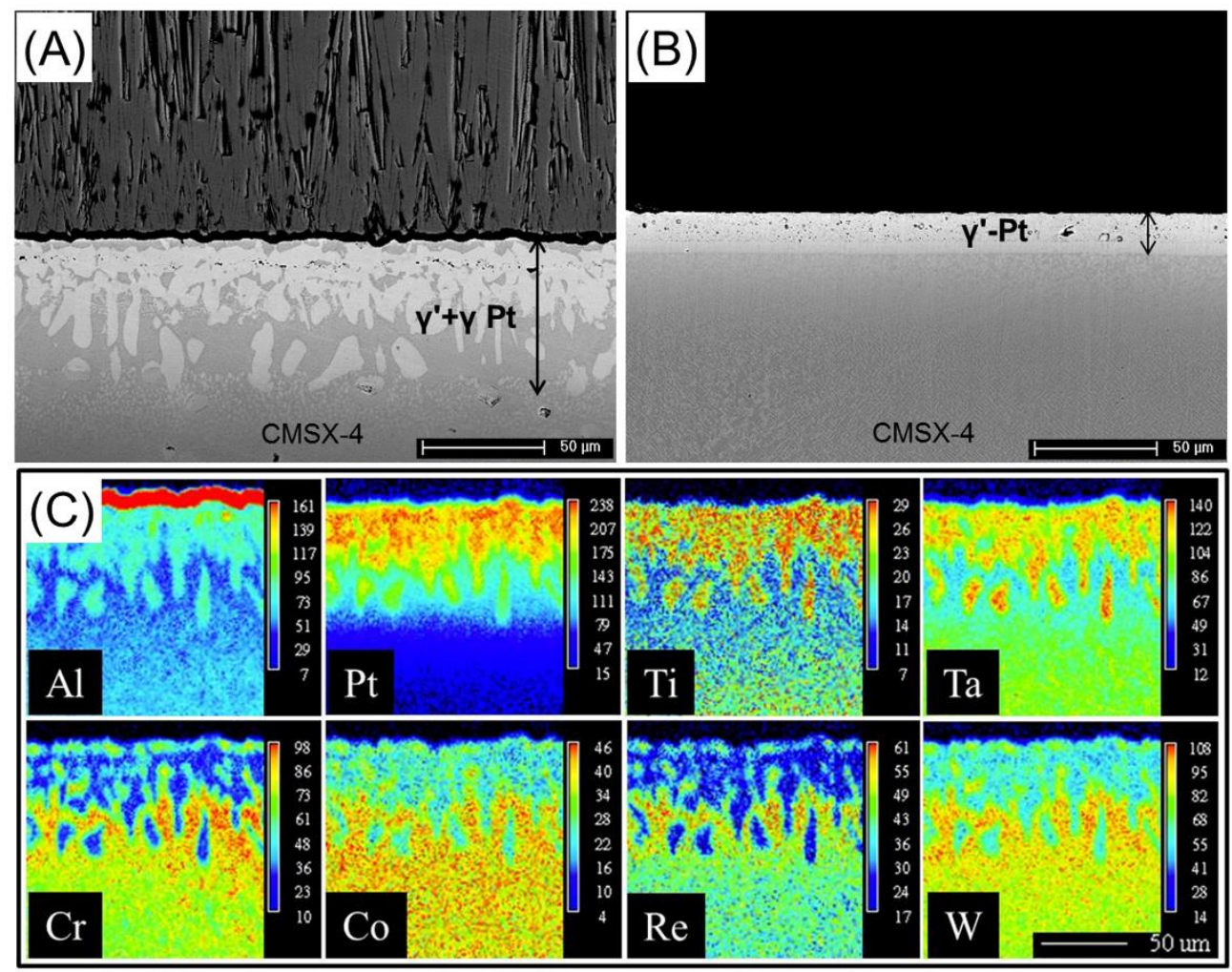

Figure 8. Cont. 


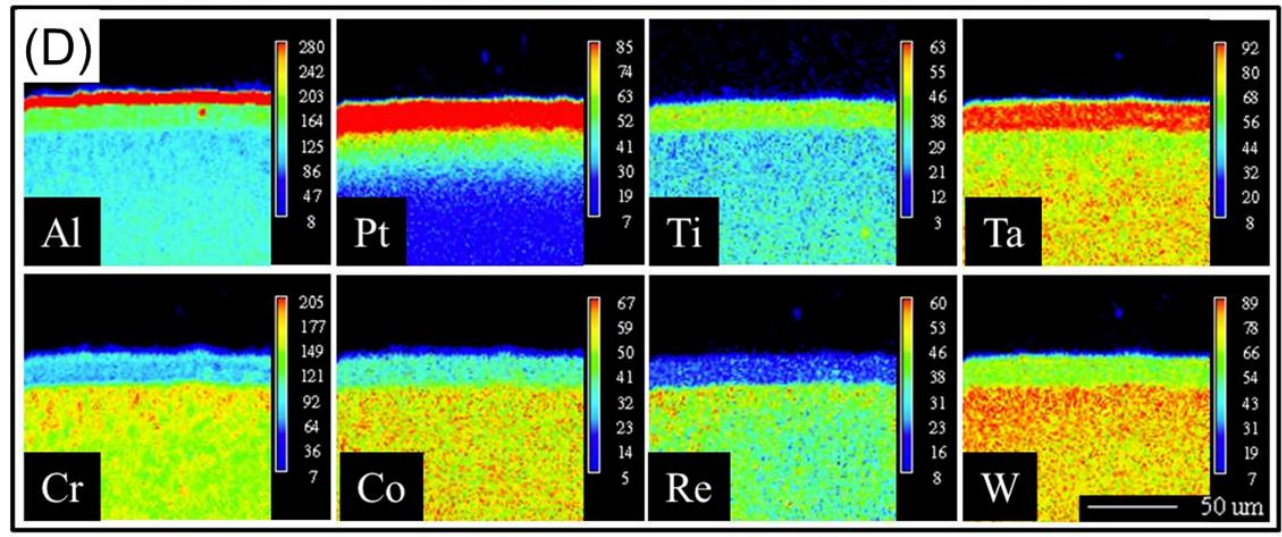

Figure 8. Cross-sectional BSE images and EPMA mappings of the $(\mathbf{A})+(\mathbf{C})$ standard Pt-diffused $\gamma / \gamma^{\prime}$ bond coat; and (B) $+\left(\right.$ D) Pt-diffused $\gamma^{\prime}$-phase bond coat after oxidation at $1150{ }^{\circ} \mathrm{C}$ for $50 \mathrm{~h}$.

\section{Discussion}

The mechanism controlling the diffusion behaviour of $\mathrm{Pt}$ in a solid solution mainly concerns with the thermodynamic and kinetic factors. The driving force for diffusion is the gradient of its chemical potential $(\mu)$ that Pt diffuses from a high- $\mu$ area to a low- $\mu$ area to reach an equilibrium. Since the formation of the Pt-diffused bond coat is obtained through a diffusion process, in which Pt diffuses into the solid solution of the CMSX-4 superalloy comprising the $\gamma$-phase and $\gamma^{\prime}$ phase, the chemical interaction between Pt and other alloying elements should play important roles on the chemical potential of $\mathrm{Pt}$, which could ultimately control its diffusion behavior.

In a non-ideal solution (real solution), the chemical potential $\mu_{i}$ of component $i$ can be expressed in terms of the thermodynamic activity, $a_{i}$ via,

$$
\mu_{i}=\mu_{i}^{0}+R T \ln a_{i}
$$

Activity (a) is a measure of the "effective concentration" of a species in a mixture, which means that the chemical potential largely depends on the activity of a real solution in the same way that it would depend on the concentration for an ideal solution.

Figure 9 shows the chemical activity $a$ of $\mathrm{Pt}$ in a binary system at $1150{ }^{\circ} \mathrm{C}$, which is calculated by the Thermo-Calc software. It can be observed that the activity of $\mathrm{Pt}$ is negatively affected by the addition of all the other alloying elements $X$ but to different extents. This figure can explain why Pt tends to diffuse from the $\gamma$-phase to the $\gamma^{\prime}$-phase that contains different elements. $\mathrm{Ni}, \mathrm{Co}, \mathrm{W}$ and $\mathrm{Cr}$, can be completely dissolved in the $\gamma-\mathrm{Pt}$ solid solution and the activity of $\mathrm{Pt}$ would decrease linearly from 1 to 0 if it was an ideal solution. On the contrary, the activity of $\mathrm{Pt}$ in the $\gamma^{\prime}-\mathrm{Pt}_{3} \mathrm{X}$ phase $(\mathrm{X}=\mathrm{Al}$ or $\mathrm{Ta}, w(\mathrm{X})=25 \mathrm{at} \%)$ is the lowest. The two dashed lines are drawn to determine whether diffusion of Pt would occur between $\gamma$ and $\gamma^{\prime}$.

1. $\Delta \mathrm{C}(\mathrm{Pt})_{\gamma-\gamma^{\prime}}=0$, which means the concentration of Pt is the same between the $\gamma$-phase and the $\gamma^{\prime}$-phase. However, the activity of $\mathrm{Pt}$ in the $\gamma$-phase is much higher than that in the $\gamma^{\prime}$-phase, as shown in Table 2. Consequently, due to the activity gradient, $\mathrm{Pt}$ will diffuse from the $\gamma$-phase to the $\gamma^{\prime}$-phase.

Table 2. The activity of $\mathrm{Pt}$ when $\Delta \mathrm{C}(\mathrm{Pt})_{\gamma-\gamma^{\prime}}=0$ at $1150^{\circ} \mathrm{C}$.

\begin{tabular}{ccccccccc}
\hline & \multicolumn{4}{c}{$\boldsymbol{\gamma}$-Pt (X) Phase } & \multicolumn{3}{c}{$\boldsymbol{\gamma}^{\prime}-\mathbf{P t}_{3} \mathbf{X}$ Phase } \\
\hline $\mathrm{X}=$ & $\mathrm{Ni}$ & $\mathrm{Re}$ & $\mathrm{Co}$ & $\mathrm{W}$ & $\mathrm{Cr}$ & $\mathrm{Al}$ & $\mathrm{Ta}$ \\
Activity of Pt & 0.715 & 0.713 & 0.571 & 0.463 & 0.335 & 0.116 & 0.0549 \\
\hline
\end{tabular}

2. $\Delta a(\mathrm{Pt})_{\gamma-\gamma^{\prime}}=0$, which means the activity of $\mathrm{Pt}$ is the same between the $\gamma$-phase and the $\gamma^{\prime}$-phase. The concentration of $\mathrm{Pt}$ in the $\gamma^{\prime}$-phase (75 at \%) is much higher than that 
in the $\gamma$-phase, as indicated by the difference in concentration of $\mathrm{Pt}\left(\mathrm{C}(\mathrm{Pt}) \gamma^{\prime}-\mathrm{C}(\mathrm{Pt})\right.$ $\gamma$ ) in Table 3. The "effective concentration" of Pt, which is defined by the activity, is largely reduced in the $\gamma^{\prime}$-phase due to the negative chemical interaction with $\mathrm{Al}$ and Ta. Consequently, $\mathrm{Pt}$ remains stable in the $\gamma^{\prime}$-phase and no diffusion of $\mathrm{Pt}$ would occur from the $\gamma^{\prime}$-phase to the $\gamma$-phase despite the concentration gradient.

Table 3. The concentration difference (at \%) when $\Delta a(\mathrm{Pt})_{\gamma-\gamma^{\prime}}=0$ at $1150{ }^{\circ} \mathrm{C}$.

\begin{tabular}{cccccc}
\hline $\mathbf{C}(\mathbf{P t})_{\gamma^{\prime}}-\mathbf{C}(\mathbf{P t})_{\gamma}$ & $\gamma(\mathbf{R e})$ & $\gamma(\mathbf{N i})$ & $\gamma(\mathbf{C o})$ & $\gamma(\mathbf{W})$ & $\gamma(\mathbf{C r})$ \\
\hline$\gamma^{\prime}(\mathrm{Al})$ & 64.8 & 38.7 & 31.1 & 20.4 & 11.8 \\
$\gamma^{\prime}(\mathrm{Ta})$ & 69.8 & 48.1 & 41.1 & 28.3 & 18.8 \\
\hline
\end{tabular}

The diffusion coefficient of $D_{P t}$ may also vary in the two phases at high temperatures, which is another factor that affects the diffusion behaviour of Pt. The diffusion coefficient of $\mathrm{Pt}$ in $\gamma-\mathrm{Ni}$ and $\gamma^{\prime}-\mathrm{Ni}_{3} \mathrm{Al}$ was studied by Y. Minamino et al. [25] and measured by Hall's method using diffusion couples. It was suggested that $D$ is indeed not constant, but largely dependent on the chemical composition and phase constitution, as well as temperature and pressure. Diffusion coefficients satisfy the following Arrhenius equation as temperature dependence,

$$
D=D_{0} \exp \{-Q / R T\}
$$

where $Q$ is the activation energy $(\mathrm{kJ} / \mathrm{mol}) ; T$ is the absolute temperature $(\mathrm{K}) ; R$ is the gas constant. $D_{0}$ and $Q$ of $\mathrm{Pt}$ in the $\gamma-\mathrm{Ni}$ and $\gamma^{\prime}-\mathrm{Ni}_{3} \mathrm{Al}$ are listed in Table 4 [25].

Table 4. The $\mathrm{D}_{0}\left(\mathrm{~cm}^{2} / \mathrm{s}\right)$ and $\mathrm{Q}(\mathrm{kJ} / \mathrm{mol})$ of Pt in the $\gamma^{\prime}-\mathrm{Ni}_{3} \mathrm{Al}$ and $\gamma-\mathrm{Ni}$.

\begin{tabular}{ccc}
\hline & $\gamma^{\prime}-\mathbf{N i}_{3} \mathbf{A l}$ & $\gamma$-Ni \\
\hline$D_{0}\left(\mathrm{~cm}^{2} / \mathrm{s}\right)$ & 7.8 & 0.35 \\
$Q(\mathrm{~kJ} / \mathrm{mol})$ & 323 & 280 \\
\hline
\end{tabular}

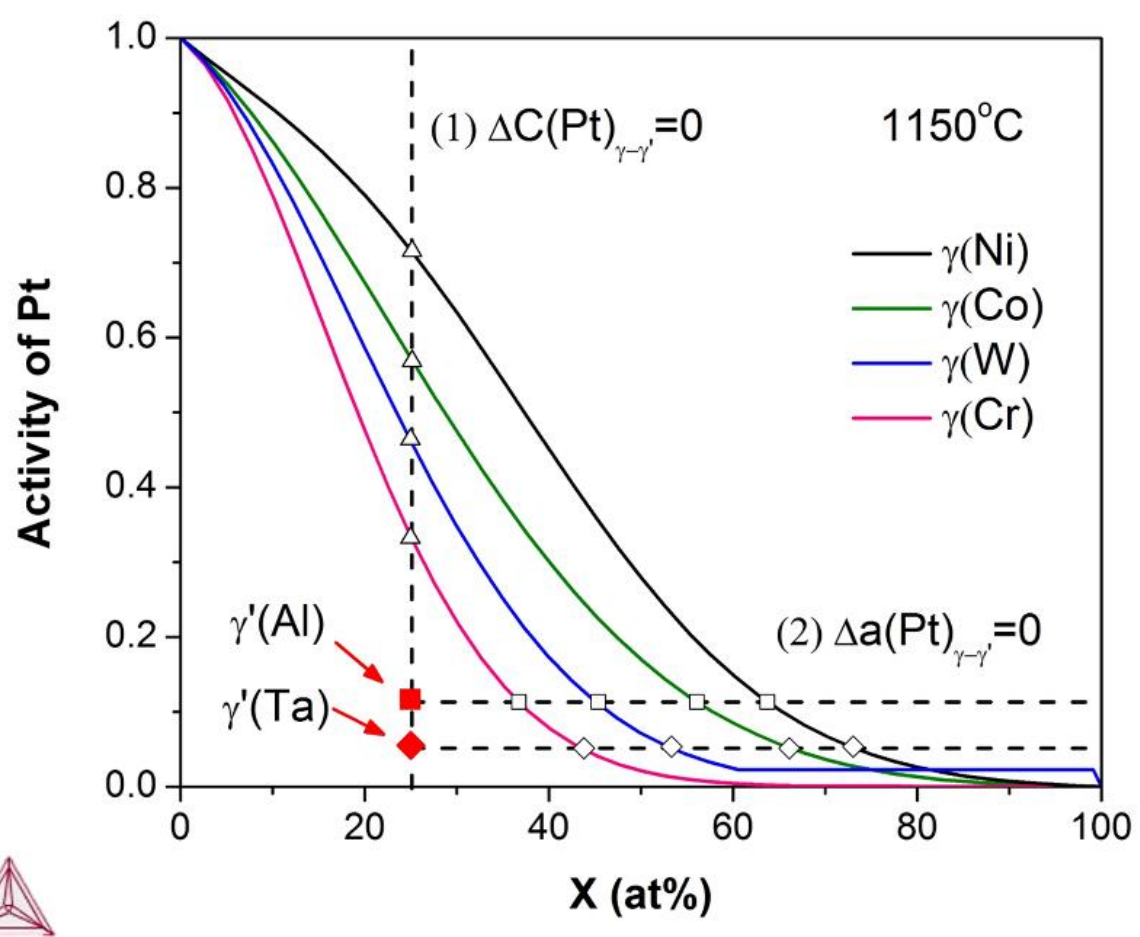

Figure 9. Dependency of the activity of Pt on the concentration of additional alloying elements at $1150^{\circ} \mathrm{C}$ in a binary system. 
Figure 10 shows the calculated diffusion coefficient of $\mathrm{Pt}$ in the $\gamma-\mathrm{Ni}$ and $\gamma^{\prime}-\mathrm{Ni}_{3} \mathrm{Al}$ at the temperatures from $950^{\circ} \mathrm{C}$ to $1150^{\circ} \mathrm{C}$ by using Equation (2) and the data from Table 4 . At $950{ }^{\circ} \mathrm{C}$, the diffusion coefficient of Pt in the $\gamma$ and $\gamma^{\prime}$ phase is nearly the same, which is $0.001 \sim 0.003 \times 10^{-10} \mathrm{~cm}^{2} / \mathrm{s}$. At $1150{ }^{\circ} \mathrm{C}$, the diffusion coefficient $D_{P t}$ in the $\gamma^{\prime}-\mathrm{Ni}_{3} \mathrm{Al}$ is $0.108 \times 10^{-10} \mathrm{~cm}^{2} / \mathrm{s}$; while $D_{P t}$ in the $\gamma-\mathrm{Ni}$ is $0.184 \times 10^{-10} \mathrm{~cm}^{2} / \mathrm{s}$, which is $70 \%$ higher than the former one. Accordingly, due to the higher diffusion coefficient in the $\gamma$-phase, the approximate diffusion length $d(d \approx \sqrt{2 D t}, t$ : time $)$ increases and results in an accelerated depletion of Pt in the $\gamma$-phase.

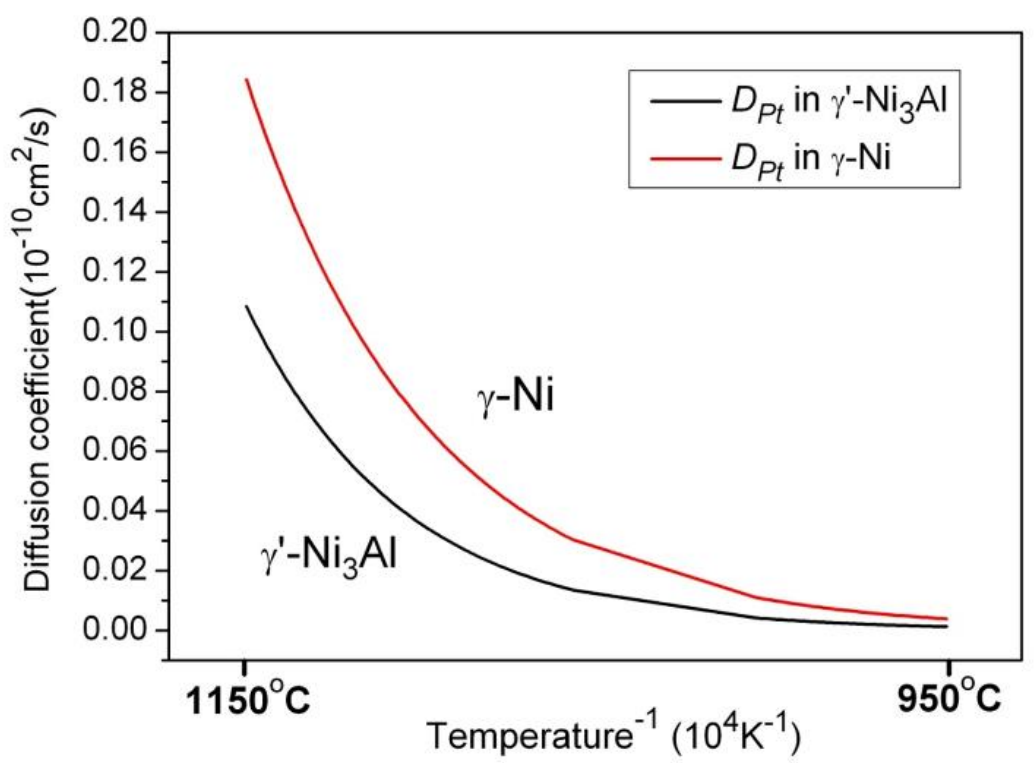

Figure 10. Diffusion coefficient of $\mathrm{Pt}$ in the $\gamma-\mathrm{Ni}$ and $\gamma^{\prime}-\mathrm{Ni}_{3} \mathrm{Al}$ phase as a function of temperature between $950{ }^{\circ} \mathrm{C}$ and $1150{ }^{\circ} \mathrm{C}$.

In this study, the depletion of Pt has been effectively mitigated with the formation of a Pt-diffused single $\gamma^{\prime}$-phase bond coat, which should therefore be able to maintain stronger adhesion at the scale/alloy interface and provide a superior oxidation resistance. More importantly, the real content of Pt in the Pt-diffused $\gamma^{\prime}$-phase bond coat is only around $3 \mu \mathrm{m}$ (the thickness of the composite layer: $14 \mu \mathrm{m}$ multiplied by the volume fraction of $\mathrm{Pt}$ in the composite layer: $23 \%$ ), which could be far less than that of the conventional Pt-diffused $\gamma / \gamma^{\prime}$ bond coat (10-12 $\left.\mu \mathrm{m}\right)$. Furthermore, the fabrication procedure of the single $\gamma^{\prime}$-phase Pt-diffused bond coat is simple and highly reproducible as only one pre-treatment process is added prior to the electroplating of Pt. To conclude, the invention of the Pt-diffused single $\gamma^{\prime}$-phase implies great potential in terms of oxidation resistance and cost savings.

\section{Conclusions}

Single phase Pt-diffused bond coats ( $\gamma$ or $\gamma^{\prime}$ phase) were fabricated by using selective etching methods on the CMSX-4 superalloy. Diffusion behaviours of Pt were investigated after long-term heat treatment, in comparison with the conventional $\gamma / \gamma^{\prime}$ bond coat. The single $\gamma$-phase bond coat accelerated the diffusion of $\mathrm{Pt}$ towards the substrate and resulted in severer depletion of Pt. By contrast, the single $\gamma^{\prime}$-phase bond coat showed superior stability of $\mathrm{Pt}$ so that the concern caused by the depletion of $\mathrm{Pt}$ towards the substrate at high temperatures could be avoided and the considerable cost of Pt could also be reduced. Thermo-Calc calculations revealed that the distinctive diffusion behaviour of $\mathrm{Pt}$ in the $\gamma^{\prime}$-phase and the $\gamma$-phase is mainly caused by the negative chemical interactions with $\mathrm{Al}$ and Ta in the $\gamma^{\prime}$-phase, as well as a much higher diffusion coefficient of Pt in the $\gamma^{\prime}$-phase at $1150{ }^{\circ} \mathrm{C}$. 
Author Contributions: Conceptualization, M.B. and Y.C.; methodology, M.B.; software, M.B.; analysis: M.B. and Y.S.; writing-review and editing, M.B., Y.C., Y.S. and P.X.; supervision and project administration, P.X. All authors have read and agreed to the published version of the manuscript.

Funding: This research received no external funding.

Institutional Review Board Statement: Not applicable.

Informed Consent Statement: Not applicable.

Data Availability Statement: Not applicable.

Acknowledgments: The authors would like to thank Brian Ralph for proof reading, Andy Wallwork, and John Charnock for the experimental assistance. The authors would also like to acknowledge David Rickerby from Rolls-Royce for the supply of TBCs sample.

Conflicts of Interest: The authors declare no conflict of interest.

\section{References}

1. Clarke, D.R.; Levi, C.G. Materials Design for the Next Generation Thermal Barrier Coatings. Annu. Rev. Mater. Res. 2003, 33, 383-417. [CrossRef]

2. Gleeson, B. Thermal Barrier Coatings for Aeroengine Applications. J. Propuls. Power 2006, 22, 375-383. [CrossRef]

3. Padture, N.P.; Gell, M.; Jordan, E.H. Thermal Barrier Coatings for Gas-Turbine Engine Applications. Science 2002, 296, 280-284. [CrossRef]

4. Evans, A.G.; Mumm, D.R.; Hutchinson, J.W.; Meier, G.H.; Pettit, F.S. Mechanisms controlling the durability of thermal barrier coatings. Prog. Mater. Sci. 2001, 46, 505-553. [CrossRef]

5. $\quad \mathrm{Wu}, \mathrm{L} . ; \mathrm{Wu}, \mathrm{R} . ; \mathrm{Zhao}, \mathrm{X}$; Xiao, P. Microstructure Parameters Affecting Interfacial Adhesion of Thermal Barrier Coatings by the EB-PVD Method. Mater. Sci. Eng. A 2014, 594, 193-202. [CrossRef]

6. Feuerstein, A.; Knapp, J.; Taylor, T.; Ashary, A.; Bolcavage, A.; Hitchman, N. Technical and Economical Aspects of Current Thermal Barrier Coating Systems for Gas Turbine Engines by Thermal Spray and EBPVD: A Review. J. Therm. Spray Technol. 2008, 17, 199-213. [CrossRef]

7. Nicholls, J.R. Advances in Coating Design for High-Performance Gas Turbines. MRS Bull. 2003, 28, 659-670. [CrossRef]

8. Rickerby, D.S.; Bell, S.R.; Wing, R.G. Method of Applying a Thermal Barrier Coating to a Superalloy Article and a Thermal Barrier Coating. U.S. Patent No. 5667663, 16 September 1997.

9. Wu, R.; Wang, X.; Atkinson, A. On the Interfacial Degradation Mechanisms of Thermal Barrier Coating Systems: Effects of Bond Coat Composition. Acta Mater. 2010, 58, 5578-5585. [CrossRef]

10. Zhao, X.; Liu, J.; Rickerby, D.; Jones, R.; Xiao, P. Evolution of Interfacial Toughness of a Thermal Barrier System With a Pt-Diffused $\gamma / \gamma^{\prime}$ Bond Coat. Acta Mater. 2011, 59, 6401-6411. [CrossRef]

11. Zhao, X.; Xiao, P. Effect of Platinum on the Durability of Thermal Barrier Systems With a $\gamma+\gamma^{\prime}$ Bond Coat. Thin Solid Films 2008, 517, 828-834. [CrossRef]

12. Pint, B.; Haynes, J.; More, K.; Schneibel, J.; Zhang, Y.; Wright, I. The Performance of Pt-Modified Alumina-Forming Coatings and Model Alloys. Superalloys 2008, 142, 641-650. [CrossRef]

13. Haynes, J.; Pint, B.; Zhang, Y.; Wright, I. The Effect of Pt Content on $\gamma-\gamma^{\prime}$ NiPtAl Coatings. Surf. Coat. Technol. 2008, 203, 413-416. [CrossRef]

14. Gleeson, B.; Mu, N.; Hayashi, S. Compositional Factors Affecting the Establishment and Maintenance of $\mathrm{Al}_{2} \mathrm{O}_{3} \mathrm{Scales}_{\text {on }} \mathrm{Ni}-\mathrm{Al}-\mathrm{Pt}$ Systems. J. Mater. Sci. 2009, 44, 1704-1710. [CrossRef]

15. Jiang, Y.; Smith, J.R. Pt Effects in $\gamma-\mathrm{Ni}(\mathrm{Al}) / \alpha-\mathrm{Al}_{2} \mathrm{O}_{3}$ Adhesion. J. Mater. Sci. 2009, 44, 1734-1740. [CrossRef]

16. Mitchell, R.; Preuss, M.; Hardy, M.; Tin, S. Influence of Composition and Cooling Rate on Constrained and Unconstrained Lattice Parameters in Advanced Polycrystalline nickel-base Superalloys. Mater. Sci. Eng. A 2006, 423, 282-291. [CrossRef]

17. Bai, M.; Xiao, P. Bond Coat. International Patent WO 2015181549 A1, 3 December 2015.

18. TCNI, T.-C. TCS Ni-Based Superalloys Database. 2011. Available online: https://www.thermocalc.com/content/uploads/ Documentation/Databases/Thermodynamic/tcni-examples-collection.pdf (accessed on 29 May 2021).

19. Andersson, J.-O.; Helander, T.; Höglund, L.; Shi, P.; Sundman, B. Thermo-Calc \& DICTRA, Computational Tools for Materials Science. Calphad 2002, 26, 273-312. [CrossRef]

20. Bai, M.; Reddy, L.; Hussain, T. Experimental and Thermodynamic Investigations on the Chlorine-Induced Corrosion of HVOF Thermal Sprayed NiAl Coatings and 304 Stainless Steels at $700{ }^{\circ}$ C. Corros. Sci. 2018, 135, 147-157. [CrossRef]

21. Pala, Z.; Bai, M.; Lukac, F.; Hussain, T. Laser Clad and HVOF-Sprayed Stellite 6 Coating in Chlorine-Rich Environment with KCl at $700{ }^{\circ}$ C. Oxid. Met. 2017, 88, 749-771. [CrossRef]

22. Bai, M.; Song, B.; Reddy, L.; Hussain, T. Preparation of MCrAlY- $\mathrm{Al}_{2} \mathrm{O}_{3}$ Composite Coatings with Enhanced Oxidation Resistance through a Novel Powder Manufacturing Process. J. Therm. Spray Technol. 2019, 28, 433-443. [CrossRef]

23. Bai, M.; Chen, Y.; Xiao, P. Investigations on the Diffusion of Platinum Between CMSX-4 Superalloy and Platinum-Enriched Bond Coat. Coatings 2021, 11, 441. [CrossRef] 
24. Völkl, R.; Glatzel, U.; Feller-Kniepmeier, M. Measurement of the Lattice Misfit in the Single Crystal Nickel Based Superalloys CMSX-4, SRR99 and SC16 by Convergent Beam Electron Diffraction. Acta Mater. 1998, 46, 4395-4404. [CrossRef]

25. Minamino, Y.; Yoshida, H.; Jung, S.B.; Hirao, K.; Yamane, T. Diffusion of Platinum and Molybdenum in Ni and Ni 3 Al. Defect Diffus. Forum 1997, 143-147, 257-262. [CrossRef] 